\title{
The Associations of Serum Vitamin D and Bone Turnover Markers with the Type and Severity of Hip Fractures in Older Women
}

\author{
Jinhui Zhao (D) \\ Qianying Cai \\ Dajun Jiang \\ Lingtian Wang \\ Shengbao Chen (D) \\ Weitao Jia \\ Department of Orthopedic Surgery, \\ Shanghai Jiaotong University Affiliated \\ Sixth People's Hospital, Shanghai 200233, \\ People's Republic of China
}

This article was published in the following Dove Press journal: Clinical Interventions in Aging
Purpose: Vitamin D (25[OH]D) status and bone turnover markers (BTMs) are considered important determinants of bone quality, which is associated with the risk of hip fractures, including both femoral neck and intertrochanteric fractures, in older adults; however, the exact relationship of 25(OH)D and BTMs with the type and severity of hip fractures remains unclear and the present study aimed to identify any specific associations.

Patients and Methods: According to the inclusion and exclusion criteria, 441 older female patients with hip fractures from 2015 to 2020 and 215 women without hip fractures were included in this cross-sectional study. According to Garden and AO/OTA classifications for femoral neck and intertrochanteric fractures, patients were divided into less severe (Garden I and Garden II; 31A1) and more severe (Garden III and Garden IV; $31 \mathrm{~A} 2$ and 31A3) fracture groups. Levels of the serum osteoblast indicator, N-terminal/mid region (N-MID); the osteoclast indicator, beta-carboxy terminal telopeptide $(\beta-\mathrm{CTX})$; and $25(\mathrm{OH}) \mathrm{D}$ were analyzed.

Results: For patients with less severe fractures, mean $25(\mathrm{OH}) \mathrm{D}$ levels were significantly higher than those with more severe fractures (17.67 vs $15.30 \mathrm{ng} / \mathrm{mL}, \mathrm{p}=0.006)$. Higher 25(OH)D levels were also observed in patients with less severe intertrochanteric fractures $(p=0.01)$. After adjustments for confounders, $25(\mathrm{OH}) \mathrm{D}$ remained a risk factor for patients with more severe fractures $(p=0.01)$, particularly those with intertrochanteric fractures $(p=0.011)$. No significant differences in BTMS were found between patients with less severe and more severe fractures. Conclusion: Levels of $25(\mathrm{OH}) \mathrm{D}$ were significantly associated with the severity of intertrochanteric, but not femoral neck, fractures. Neither 25(OH)D nor BTMs were associated with the type of hip fracture in older women. Separate consideration of intertrochanteric and femoral neck fractures may be appropriate when investigating the clinical association between $25(\mathrm{OH}) \mathrm{D}$ and the severity of hip fractures in older women.

Keywords: 25(OH)D, bone turnover markers, femoral neck fractures, intertrochanteric fractures, fracture severity

\section{Introduction}

Hip fractures are among the most common injuries in older adults, and are often referred to as "the last fracture of the elderly." With the accelerated aging of the global population, the incidence of hip fractures among older adults continues to rise. It is estimated that 1.6 million hip fractures occur worldwide each year, and this number is expected to reach 2.5 million by $2050 .{ }^{1}$ Serum vitamin D status is essential for bone mineralization and for the subsequent maintenance of bone quality, through its role in the regulation of skeletal metabolism equilibrium. Vitamin D maintains calcium homeostasis through the binding
Shengbao Chen

Department of Orthopedic Surgery,

Shanghai Jiaotong University Affiliated

Sixth People's Hospital, Shanghai 200233,

People's Republic of China

Tel +8618930173388

Fax $+86021-6470136 I$

Email jiaweitao@shsmu.edu.cn;

shengbaochen@I63.com
Clinical Interventions in Aging 2020:15 197|-1978

1971

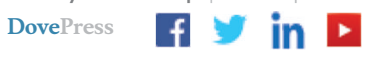

http://doi.org/| 0.2147/CIA.S271904 
of $1,25(\mathrm{OH})_{2} \mathrm{D}_{3}$ to vitamin $\mathrm{D}$ receptors. However, the half-life of $1,25(\mathrm{OH})_{2} \mathrm{D}_{3}$, the active form of vitamin $\mathrm{D}$, is too short to be used to assess physiological vitamin $\mathrm{D}$ status. ${ }^{2}$ Therefore, 25-hydroxyvitamin D $(25[\mathrm{OH}] \mathrm{D})$ is usually measured to evaluate vitamin D status, as $25(\mathrm{OH}) \mathrm{D}$ levels reflect the activity of $1,25(\mathrm{OH})_{2} \mathrm{D}_{3}$. Bone formation biomarkers are synthesized by osteoblasts and reflect osteoblast function. Furthermore, bone resorption markers are degradation products of type I collagen. ${ }^{3}$ Numerous previous studies have demonstrated that $25(\mathrm{OH}) \mathrm{D}$ and bone turnover markers (BTMs) are associated with the incidence of hip fractures in older adults. ${ }^{4-10}$

Although hip fractures in older people include two distinct anatomical types, femoral neck and intertrochanteric, most studies have evaluated them as though they were a homogenous entity. ${ }^{11,12}$ Nevertheless, there are noteworthy differences in many aspects of these two types of fracture, including epidemiological characteristics, bone composition and geometry, treatment methods, and clinical prognosis. ${ }^{13-17}$ Therefore, concerns have been raised that the results of studies that do not distinguish between the types of hip fracture may be biased. ${ }^{18}$ The clinical importance of distinguishing among hip fractures of differing type and severity becomes apparent in the formulation of potential fracture-specific treatment strategies and determination of prognosis. ${ }^{17,19}$ Therefore, investigation of the risk factors associated with the type and severity of hip fractures in older adults is necessary, and will contribute to clinical understanding of metabolic mechanisms associated with hip fractures, and inform subsequent decisions.

The levels of the BTMs in women begin to increase in perimenopause. $^{20}$ Therefore, elderly women are more likely to have higher levels of BTMs. Therefore, in the current study, we conducted a retrospective analysis of elderly female patients with hip fractures, which were classified into two fracture types and severities based on the Garden (I-IV) and OA/OTA (31A1, 31A2, 31A3) fracture classification systems. ${ }^{21}$

The distinction between various fracture types is of particular importance because a better understanding of factors associated with each fracture subtype and level of severity could help to guide high-value clinical management. $^{22}$ To date, there has been limited research investigating the potential relationships of $25(\mathrm{OH}) \mathrm{D}$ and BTMs with the type and severity of hip fractures in older women. The objective of the present study was to systematically investigate whether serum $25(\mathrm{OH}) \mathrm{D}$ and BTMs are risk factors for the type and severity of hip fractures in elderly women.

\section{Patients and Methods Subjects}

Female patients (aged $\geq 65$ years) who had sustained hip fractures (including femoral neck and intertrochanteric fractures) with a low-energy injury from November 24, 2015 to May 20, 2020, were recruited for inclusion in a cross-sectional study. The fractures were all nonpathological, and metabolic-related diseases (including thyroid disease, renal insufficiency, diabetes and tumors) were ruled out. Of 552 potential participants, 111 were excluded because of a history of supplementation with calcium, vitamin $\mathrm{D}$, or the administration of antiosteoporosis drugs; a history of dementia, stroke, or previous fractures; or a lack of data. Eventually, 441 female patients were included in the present study. Furthermore, 215 women (aged $\geq 65$ years, without hip fractures) who came to our hospital for routine examination, and met the inclusion and exclusion criteria mentioned above were enrolled as a healthy control group. All participants were aware of the purpose of the study and provided signed informed consent. The study was reviewed by the Ethics Committee of Shanghai Sixth People's Hospital (approval number: 2017-152) and registered in the China Clinical Trial Center (registration number: "ChiCTR-ONC $-17,013,389$ "). The study protocol was in accordance with the principles of the Declaration of Helsinki (as revised in Brazil 2013).

\section{Assays}

Femoral neck fractures were classified according to the degree of fracture displacement (Garden classification), while intertrochanteric fractures were grouped according to the fragment and lateral cortex (AO/OTA classification, version 2018). Less severe fractures were referred to as non-displaced or stable fractures (Garden I and Garden II; 31A1), and more severe fractures were referred to as displaced or unstable fractures (Garden III and Garden IV; 31A2 and 31A3). The exact fracture type and severity were independently assessed by three experienced orthopedic surgeons, who all agreed with the final classification of fractures. The bone resorption marker, beta-carboxy terminal telopeptide $(\beta-\mathrm{CTX})$, and the bone formation marker, N-terminal/mid region (N-MID), were measured after overnight fasting both in patients with fractures and 
healthy controls. ${ }^{5,23,24}$ Serum concentrations of $\beta$-CTX, N-MID, and 25(OH)D were measured using a Roche electrochemiluminescence system (Cobas E602; Roche Diagnostics, Basel, Switzerland). According to the Endocrine Society Task Force Clinical Practice Guideline $(2011),{ }^{25}$ vitamin $\mathrm{D}$ deficiency was determined at a concentration of $<50 \mathrm{nmol} / \mathrm{L}(20 \mathrm{ng} / \mathrm{mL}) 25(\mathrm{OH}) \mathrm{D}$, and vitamin $\mathrm{D}$ insufficiency at $50-75 \mathrm{nmol} / \mathrm{L}(21-29 \mathrm{ng} /$ mL) $25(\mathrm{OH}) \mathrm{D}$.

\section{Statistical Analysis}

Baseline data and laboratory indicators were compared for different fracture types and severities in all subjects and patient subgroups (femoral neck and intertrochanteric fracture groups). Continuous variables were expressed as the mean \pm standard deviation, and categorical variables as percentages. The normality of continuous variables was tested. The significance of differences between groups was then evaluated using the independent $t$-test for two samples, Mann-Whitney test, or analysis of variance (ANOVA). Qualitative data were tested using the Chisquare test. Logistic regression analysis was performed to determine which variables were independently associated with the type and severity of hip fracture. Data analysis was performed using the SPSS software (version 25). The p-values were two-sided, and a value $<0.05$ was considered statistically significant.

\section{Results}

\section{Participant Demographic and Clinical Characteristics}

A total of 441 older female patients with hip fractures and 215 women without hip fractures were included in the present study. Among the patients with hip fractures, $266(60.32 \%)$ had femoral neck fractures, of which 95 (35.71\%) were non-displaced and 171 (64.29\%) were displaced. A total of $175(39.68 \%)$ patients had intertrochanteric factures, among which 55 (31.43\%) were stable and $120(68.57 \%)$ were unstable. A total of $150(34.01 \%)$ patients had less severe fractures, and 291 (65.99\%) patients had more severe fractures, respectively. As shown in Tables 1 and 2, patients with femoral neck fractures were significantly younger (mean age, 77.54 vs 82.98 years, $\mathrm{p}<0.001, t$-test) and taller than those with intertrochanteric fractures $(\mathrm{p}=0.001)$. Furthermore, patients with more severe fractures $(65.99 \%)$ were older, had lower vitamin D levels, and a higher proportion of vitamin $\mathrm{D}$ deficiency.

No significant differences in weight, body mass index (BMI), $\beta$-CTX, or N-MID levels, were detected among patients with different fracture types or severities $(p>0.05)$. However, significant differences were noted in age, height, $\beta$-CTX and $25(\mathrm{OH}) \mathrm{D}$ levels, and proportion of vitamin $\mathrm{D}$ deficient individuals, between patients with femoral neck or intertrochanteric fractures and those without hip fractures $(\mathrm{p}$ $<0.001$ for both patients with femoral neck fractures and intertrochanteric fractures vs those without fractures). Similar results were observed in comparisons of patients with both less and more severe hip fractures to those without hip fractures $(p$ $<0.001$ vs women without fractures).

\section{Association Between Patient Characteristics and Hip Fracture Stratified According to Type and Severity}

The clinical characteristics of fracture severity and fracture type subgroups are presented in Table 3 . The proportion of patients with more severe fractures among those with either fracture types was similar $(64.29 \%$ and $68.57 \%$ for femoral neck and intertrochanteric fractures, respectively, $\mathrm{p}=0.353)$. In the femoral neck fracture group, patients with less severe fractures were younger than those with more severe fractures (mean age, 75.68 vs 78.57 years, $p=0.003$ ); and no significant differences were detected between these two groups in height, weight, BMI, $\beta$-CTX, N-MID, or 25(OH)D ( $p>0.05$ ). In the intertrochanteric fracture group, lower 25(OH)D levels and a higher proportion of vitamin $\mathrm{D}$ deficient individuals were found in patients with more severe fractures (18.31 vs $14.63 \mathrm{ng} / \mathrm{mL}, \mathrm{p}=0.010 ; 61.82 \%$ vs $78.33 \%, \mathrm{p}=0.022$ ).

\section{Logistic Regression Analysis}

In unadjusted logistic regression models for all subjects, age (crude odds ratio $(\mathrm{OR})=1.046,95 \%$ confidence interval $(\mathrm{CI})$ $=1.019-1.073, \mathrm{p}=0.001)$ and $25(\mathrm{OH}) \mathrm{D}$ levels (crude $\mathrm{OR}=$ $0.968,95 \% \mathrm{CI}=0.946-0.991, \mathrm{p}=0.006)$ were associated with the incidence of more severe hip fractures. Furthermore, in subgroup analyses, age (crude OR $=1.055,95 \% \mathrm{CI}=$ $1.018-1.093, \mathrm{p}=0.003)$ and 25(OH)D levels (crude $\mathrm{OR}=$ $0.955,95 \% \mathrm{CI}=0.920-0.990, \mathrm{p}=0.013$ ) were associated with more severe femoral neck fractures and more severe intertrochanteric fractures, respectively. After adjustment for confounding factors, analysis of all subjects indicated that age (adjusted $\mathrm{OR}=1.043,95 \% \mathrm{CI}=1.015-1.072, \mathrm{p}=0.002$ ) 
Table I Characteristics of Included Patients with Respect to Hip Fracture Type

\begin{tabular}{|l|l|l|l|}
\hline \multirow{2}{*}{} & \multicolumn{2}{|l|}{ Older Adult Patients with Hip Fracture } & \multirow{2}{*}{ Healthy Controls (n = 215) } \\
\cline { 2 - 4 } & FN Group (n= 266) & IT Group (n = 175) & \\
\hline Age (years) & $77.54 \pm 7.53^{*}$, & $82.98 \pm 7.41^{\#}$ & $73.63 \pm 6.12$ \\
Height $(\mathrm{cm})$ & $158.20 \pm 5.07^{* \#}$ & $156.55 \pm 5.36^{\#}$ & $152.70 \pm 6.38$ \\
Weight $(\mathrm{kg})$ & $55.78 \pm 10.02$ & $55.84 \pm 12.95$ & $54.07 \pm 8.98$ \\
BMI $\left(\mathrm{kg} / \mathrm{m}^{2}\right)$ & $22.28 \pm 3.88^{\#}$ & $22.79 \pm 5.46$ & $23.18 \pm 3.62$ \\
$\beta-C T X(\mathrm{ng} / \mathrm{L})$ & $523.87 \pm 336.10^{\#}$ & $565.16 \pm 347.66^{\#}$ & $337.08 \pm 269.02$ \\
N-MID $(\mathrm{ng} / \mathrm{mL})$ & $15.61 \pm 9.04$ & $15.77 \pm 9.26$ & $14.93 \pm 7.67$ \\
$25(\mathrm{OH}) \mathrm{D}(\mathrm{ng} / \mathrm{mL})$ & $16.32 \pm 8.32^{\#}$ & $15.79 \pm 8.82^{\#}$ & $28.81 \pm 10.12$ \\
$<20 \mathrm{ng} / \mathrm{mL}$ & $195(73.31 \%)^{\#}$ & $128(73.14 \%)^{\#}$ & $47(21.86 \%)$ \\
\hline
\end{tabular}

Notes: ${ }^{*} p<0.05$ vs intertrochanteric fracture. ${ }^{\#} p<0.05$ vs no hip fractures. Data are presented as the mean \pm standard deviation.

Abbreviations: FN, femoral neck fracture; IT, intertrochanteric fracture; $\beta$-CTX, C-terminal telopeptide of type-I collagen; N-MID, N-MID fragment; BMI, body mass index.

Table 2 Characteristics of Patients with Respect to Hip Fracture Severity

\begin{tabular}{|c|c|c|c|}
\hline $\begin{array}{l}\text { Patients with Hip Fracture }(n= \\
44 I)\end{array}$ & $\begin{array}{l}\text { Less Severe Fracture }(n= \\
\text { I50) }\end{array}$ & $\begin{array}{l}\text { More Severe Fracture }(n= \\
\text { 29I) }\end{array}$ & $\begin{array}{l}\text { No Hip Fractures }(n= \\
215)\end{array}$ \\
\hline Age (years) & $77.88 \pm 7.64^{* \#}$ & $80.63 \pm 7.93^{\#}$ & $73.63 \pm 6.12$ \\
\hline Height $(\mathrm{cm})$ & $157.59 \pm 5.26^{\#}$ & $157.53 \pm 5.24^{\#}$ & $152.70 \pm 6.38$ \\
\hline Weight (kg) & $56.72 \pm 12.24^{\#}$ & $55.34 \pm|0.7|$ & $54.07 \pm 8.98$ \\
\hline BMI $\left(\mathrm{kg} / \mathrm{m}^{2}\right)$ & $22.89 \pm 5.46$ & $22.27 \pm 4.03^{\#}$ & $23.18 \pm 3.62$ \\
\hline$\beta-C T X(n g / L)$ & $509.79 \pm 352.07^{\#}$ & $555.96 \pm 334.59^{\#}$ & $337.08 \pm 269.02$ \\
\hline N-MID (ng/mL) & $15.92 \pm 10.88$ & $15.55 \pm 8.07$ & $14.93 \pm 7.67$ \\
\hline $25(\mathrm{OH}) \mathrm{D}(\mathrm{ng} / \mathrm{mL})$ & $17.67 \pm 8.64^{* \#}$ & $15.30 \pm 8.35^{\#}$ & $28.81 \pm 10.12$ \\
\hline$<20 \mathrm{ng} / \mathrm{mL}$ & $100(66.67 \%)^{\#}$ & $223(76.63 \%)^{\#}$ & $47(21.86 \%)$ \\
\hline
\end{tabular}

Notes: ${ }^{*} p<0.05$ vs more severe fracture ${ }^{\#} p<0.05$ vs no hip fractures. Data are presented as the mean \pm standard deviation.

Abbreviations: $\beta$-CTX, C-terminal telopeptide of type-I collagen; N-MID, N-MID fragment; BMI, body mass index.

and 25(OH)D levels (adjusted OR $=0.970,95 \% \mathrm{CI}=$ $0.948-0.994, p=0.013$ ) remained risk factors for hip fracture severity. Furthermore, age (adjusted OR $=1.048,95 \%$ $\mathrm{CI}=1.010-1.087, \mathrm{p}=0.014)$ remained an independent risk factor for femoral neck fracture $(\mathrm{FN})$ and $25(\mathrm{OH}) \mathrm{D}$ levels (adjusted OR $=0.952,95 \% \mathrm{CI}=0.917-0.989, \mathrm{p}=0.011$ ) remained an independent factor associated with intertrochanteric fracture (IT) (Table 4).

Table 3 Characteristics of 44I Patients with Different Hip Fracture Type and Severity

\begin{tabular}{|c|c|c|c|c|}
\hline & \multicolumn{2}{|c|}{ FN Group $(n=266)$} & \multicolumn{2}{|c|}{ IT Group (n = I75) } \\
\hline & Less Severe & More Severe & Less Severe & More Severe \\
\hline Patients (n) & 95 (35.7।\%) & $|7|$ (64.29\%) & $55(31.43 \%)$ & $120(68.57 \%)$ \\
\hline Age (years) & $75.68 \pm 7.06^{*}$ & $78.57 \pm 7.60^{*}$ & $81.67 \pm 7.16$ & $83.58 \pm 7.47$ \\
\hline Height $(\mathrm{cm})$ & $158.43 \pm 5.46$ & $158.08 \pm 4.85$ & $156.15 \pm 4.60$ & $156.74 \pm 5.68$ \\
\hline Weight (kg) & $56.22 \pm 9.74$ & $55.54 \pm 10.20$ & $57.57 \pm 15.72$ & $55.04 \pm 11.45$ \\
\hline BMI $\left(\mathrm{kg} / \mathrm{m}^{2}\right)$ & $22.41 \pm 3.86$ & $22.21 \pm 3.90$ & $23.73 \pm 7.44$ & $22.36 \pm 4.23$ \\
\hline$\beta-C T X(n g / L)$ & $480.64 \pm 345.49$ & $547.89 \pm 329.34$ & $560.14 \pm 360.80$ & $567.46 \pm 343.00$ \\
\hline N-MID (ng/mL) & $16.07 \pm 12.04$ & $15.36 \pm 6.85$ & $15.66 \pm 8.60$ & $15.83 \pm 9.58$ \\
\hline $25(\mathrm{OH}) \mathrm{D}(\mathrm{ng} / \mathrm{mL})$ & $17.30 \pm 8.31$ & $15.77 \pm 8.31$ & $|8.3| \pm 9.23^{*}$ & $|4.63 \pm 8.4|^{*}$ \\
\hline $25(\mathrm{OH}) \mathrm{D}<20 \mathrm{ng} / \mathrm{mL}$ & $66(69.47 \%)$ & 129 (75.44\%) & $34(61.82 \%)^{*}$ & 94 (78.33\%)* \\
\hline
\end{tabular}

Note: *Significant difference between patients with less severe and more severe fractures, stratified by fracture type ( $p<0.05, t$-test).

Abbreviations: $\beta$-CTX, C-terminal telopeptide of type-I collagen; N-MID, N-MID fragment; FN, femoral neck fracture; IT, intertrochanteric fracture; BMI, body mass index. 
Table 4 Logistic Regression Analysis of Factors Associated with Severity of Total Hip Fractures and Hip Fracture Subtype

\begin{tabular}{|c|c|c|c|c|}
\hline \multicolumn{5}{|c|}{ Hip Fractures $(n=44 I)$} \\
\hline & Crude OR $(95 \% \mathrm{Cl})$ & $P$ value & Adjusted OR (95\% Cl) & $P$ value \\
\hline Age & $1.046(1.019-1.073)$ & 0.001 & $1.043(1.015-1.072)$ & 0.002 \\
\hline$\beta-C T X$ & $1.000(1.000-1.001)$ & 0.180 & $1.000(1.000-1.001)$ & 0.292 \\
\hline N-MID & $0.996(0.975-1.017)$ & 0.690 & $0.992(0.970-1.014)$ & 0.452 \\
\hline $25(\mathrm{OH}) \mathrm{D}$ & $0.968(0.946-0.991)$ & 0.006 & $0.970(0.948-0.994)$ & 0.013 \\
\hline \multicolumn{5}{|c|}{$F N(n=266)$} \\
\hline & Crude OR $(95 \% \mathrm{Cl})$ & $P$ value & Adjusted OR (95\% Cl) & $P$ value \\
\hline Age & $1.055(1.018-1.093)$ & 0.003 & $1.048(1.010-1.087)$ & 0.014 \\
\hline$\beta$-СТX & $1.001(1.000-1.001)$ & 0.122 & $1.001(1.000-1.002)$ & 0.150 \\
\hline N-MID & $0.991(0.965-1.019)$ & 0.539 & $0.987(0.960-1.016)$ & 0.373 \\
\hline $25(\mathrm{OH}) \mathrm{D}$ & $0.979(0.950-1.008)$ & 0.155 & $0.982(0.952-1.013)$ & 0.257 \\
\hline \multicolumn{5}{|c|}{ IT $(n=175)$} \\
\hline & Crude OR $(95 \% \mathrm{Cl})$ & $P$ value & Adjusted OR (95\% Cl) & $P$ value \\
\hline Age & I.035 (0.99I-I.08I) & 0.116 & $1.035(0.990-1.083)$ & 0.133 \\
\hline$\beta$-CTX & $1.000(0.999-1.001)$ & 0.897 & $1.000(0.999-1.001)$ & 0.910 \\
\hline N-MID & $1.002(0.968-1.038)$ & 0.903 & $0.998(0.963-1.035)$ & 0.929 \\
\hline $25(\mathrm{OH}) \mathrm{D}$ & $0.955(0.920-0.990)$ & 0.013 & $0.952(0.917-0.989)$ & 0.011 \\
\hline
\end{tabular}

Note: Results are adjusted for age, height, weight and history of hypertension.

Abbreviations: FN, femoral neck fracture; IT, intertrochanteric fracture; $\beta$-CTX, C-terminal telopeptide of type-I collagen; N-MID, N-MID fragment; OR, odds ratio; CI, confidence interval.

\section{Discussion}

In the present study, we found that serum $25(\mathrm{OH}) \mathrm{D}$ was a risk factor for the incidence of hip fractures in older women but not for types of hip fracture. Furthermore, 25 $(\mathrm{OH}) \mathrm{D}$ levels were associated with the severity of intertrochanteric, but not femoral neck, fractures. Numerous studies have explored associations between metabolic indicators and the incidence of hip fractures in older adults. ${ }^{9,10,26}$ However, few investigations have been focused on risk factors related to hip fracture type and severity, and particularly the severity in subgroups of hip fracture type among older women. A better understanding of such associations could also help to guide healthcare providers and patient counselling. To our knowledge, the present study is the first to analyze the relationships of serum 25(OH)D and BTMs with hip fractures of different type and severity in older women.

Vitamin D deficiency is a major public health issue worldwide among all age groups, ${ }^{27}$ and is more prevalent among the elderly, because they are less active and seldom go outdoors to benefit from adequate exposure to sunlight. ${ }^{28}$ The present study showed that women with either femoral neck or intertrochanteric fractures had lower levels of 25(OH)D and were more frequently deficient in vitamin $\mathrm{D}$, compared with women without hip fractures. These results are consistent with those of previous studies, which have shown that $25(\mathrm{OH}) \mathrm{D}$ is associated with the occurrence of hip fracture in older adults. ${ }^{2,29,30}$ Whether the level of 25(OH)D differs significantly in patients who sustain different types of hip fracture remains controversial, ${ }^{31,32}$ and a few studies have investigated the association between 25(OH)D levels and fracture severity.

Based on the existing evidence, 25(OH)D levels may not be related to the type of hip fracture in older women, as both the level of $25(\mathrm{OH}) \mathrm{D}$ and the proportion of vitamin D deficient individuals were similar among patients with femoral neck fractures and those with intertrochanteric fractures. However, we detected a significant difference in 25(OH)D levels between patients with hip fractures of differing severity. These findings indicate that 25(OH)D levels may be more closely associated with hip fracture severity. Intertrochanteric fractures were significantly associated with 25(OH)D levels, whereas femoral neck fractures were not. These findings indicate that an analysis of $25(\mathrm{OH}) \mathrm{D}$ may be more relevant to 
intertrochanteric fracture severity. Differences in the percentages of intertrochanteric fractures among the total population may have resulted in a statistical anomaly regarding the relationship between $25(\mathrm{OH}) \mathrm{D}$ levels and the severity of hip fractures in older women. Alternatively, different pathophysiological mechanisms may underly femoral neck and intertrochanteric fractures, ${ }^{14}$ resulting in the differences observed in the relationship between $25(\mathrm{OH}) \mathrm{D}$ levels and severity of the two types of fracture.

Intertrochanteric fractures are assumed to be more dependent on high levels of skeletal metabolic activity than femoral neck fractures, because of the large proportion of metabolically active trabecular bone in the intertrochanteric region. ${ }^{33,34}$ Furthermore, the intertrochanteric region is superficial, making it more likely to sustain a fracture in response to external trauma. Moreover, 25 (OH)D levels are positively correlated with bone quality, ${ }^{35}$ which plays a major role in the severity of fractures. Hence, the relationship between $25(\mathrm{OH}) \mathrm{D}$ levels and the severity of intertrochanteric fractures is logical.

In contrast, the anatomical and biomechanical environment of the femoral neck is more complex, as it locates in the intracapsular region. In that area, the energy of a direct impact to the hip is dissipated, when transmitted from the intertrochanteric region to the femoral neck. Hence, the incidence of femoral neck fractures is more likely to dependent on a combination of factors, rather than a sole metabolic factor. These findings lead to uncertainty regarding an association between $25(\mathrm{OH}) \mathrm{D}$ levels and the severity of femoral neck fractures. Therefore, it may be inappropriate to evaluate hip fractures as a homogenous group when investigating the association between $25(\mathrm{OH})$ $\mathrm{D}$ levels and the severity of hip fractures, particularly in older women.

Numerous studies have investigated whether BTMs can predict the incidence of hip fractures in older patients; ${ }^{5-7,26}$ however, no specific conclusions have been drawn. Compared with women without fractures, higher levels of $\beta$-CTX were observed in women with either femoral neck or intertrochanteric fractures in the present study, indicating an association between an active state of bone resorption and an increased risk of hip fractures. The exact relationship warrants further investigation.

Recently, concerns have been expressed that published results regarding the relationship between BTMs and the incidence of hip fractures in older adults may be biased, owing to a lack of separate analysis based on different hip fracture types. ${ }^{18}$ No significant differences in N-MID or $\beta$-CTX levels were found between patients with different hip fracture types and those with differences in severity in the present study, indicating that the levels of BTMs are not directly associated with the type and severity of hip fracture in elderly women. The BTMs are highly sensitive and may be affected by many factors, including circadian rhythms, seasonal changes, diet, geography, and ethnicity. ${ }^{23}$ Therefore, BTMs may be a sensitive, but not a specific, indicator for evaluation of the type and severity of hip fractures in older women. Further, it may be difficult to evaluate the status of recent stable skeletal metabolism, based on samples collected at a single time point. The adoption of international reference standards may help to resolve uncertainties regarding the clinical application of these markers. Patients with intertrochanteric fractures were found to be older than those with femoral neck fractures. ${ }^{22,36}$ Further, patients with more severe hip fractures were also found to be older than those with less severe fractures, particularly those with femoral neck fractures, indicating that age is related to both the type and severity of femoral neck fractures; however, a previous study reported that patients with more severe hip fractures were similar in age to those with less severe fractures. ${ }^{32}$ This difference could be attributed to the percentages of patients with different hip fracture types among the total study population, further highlighting the importance of separate investigations of hip fracture based on different types among older adults. Moreover, patients with femoral neck fractures were taller than those with intertrochanteric fractures, indicating that height may be associated with hip fracture type. No significant differences in the patient height were detected, according to fracture severity. Two previous studies examined height in relation to fracture severity, and reported conflicting results. ${ }^{37,38}$ The subjects included in the study of Cauley et al were all older white women, while those in the study of Chen et al and those in the present investigation were all elderly Chinese women. ${ }^{37,38}$ Hence, the observed discrepancies may be attributable to differences in ethnicity.

The present study has some limitations. The present findings were based on older female subjects and might not be applicable to male subjects. Determining the type and severity of hip fractures remained somewhat subjective, despite blinding of the investigators. Age was not matched when patients with less and more severe femoral neck fractures were compared. Furthermore, the sample 
size was relatively small, and previous investigations may have used different hip fracture classification systems.

\section{Conclusion}

In conclusion, serum $25(\mathrm{OH}) \mathrm{D}$ is a risk factor for the incidence of hip fractures in older women, but not for types of hip fracture. Furthermore, 25(OH)D levels are associated with the severity of intertrochanteric fractures, but not femoral neck, fractures. When investigating the relationship between $25(\mathrm{OH}) \mathrm{D}$ levels and hip fracture severity in older adults, the results may be biased if intertrochanteric and femoral neck fractures are considered as a homogenous group. No significant differences in BTMs were detected between groups, regardless of fracture type or severity. However, higher levels of $\beta$-CTX were detected in patients with hip fractures compared those in the control population.

\section{Data Sharing Statement}

No additional unpublished data are available.

\section{Funding}

W.-T.J. received funding from the National Key Research and Development Program of China (NO.2018YFC1106300), Shanghai Municipal Education Commission-Gaofeng Clinical Medicine Grant Support (Grant NO.20172026), and Shanghai Talents Development Fund (Grant NO.2017035).

\section{Disclosure}

The authors report no conflicts of interest in this work. Weitao Jia and Shengbao Chen are corresponding coauthors.

\section{References}

1. Gullberg B, Johnell O, Kanis JA. World-wide projections for hip fracture. Osteoporos Int. 1997;7(5):407-413. doi:10.1007/p100004148

2. Torbergsen AC, Watne LO, Wyller TB, et al. Vitamin K1 and 25(OH) $\mathrm{D}$ are independently and synergistically associated with a risk for hip fracture in an elderly population: a case control study. Clin Nutr. 2015;34(1):101-106. doi:10.1016/j.clnu.2014.01.016

3. Garnero P, Ferreras M, Karsdal MA, et al. The type I collagen fragments ICTP and CTX reveal distinct enzymatic pathways of bone collagen degradation. $J$ Bone Miner Res. 2003;18(5):859-867. doi:10.1359/jbmr.2003.18.5.859

4. Johansson H, Odén A, Kanis JA, et al. A meta-analysis of reference markers of bone turnover for prediction of fracture. Calcif Tissue Int. 2014;94(5):560-567. doi:10.1007/s00223-014-9842-y

5. Shiga T, Tsuji Y, Fujioka M, Kubo T. Risk factors for hip fracture in Japanese elderly women with osteoporosis: applicability of biochemical markers in bone turnover. Geriatr Gerontol Int. 2009;9(1):69-74. doi:10.1111/j.1447-0594.2008.00510.x
6. Chapurlat RD, Garnero P, Bréart G, Meunier PJ, Delmas PD. Serum type I collagen breakdown product (serum CTX) predicts hip fracture risk in elderly women: the EPIDOS study. Bone. 2000;27 (2):283-286. doi:10.1016/s8756-3282(00)00325-2

7. Dai Z, Wang R, Ang LW, Yuan JM, Koh WP. Bone turnover biomarkers and risk of osteoporotic hip fracture in an Asian population. Bone. 2016;83:171-177. doi:10.1016/j.bone.2015.11.005

8. Curtis EM, Harvey NC, D'Angelo S, et al. Bone mineral content and areal density, but not bone area, predict an incident fracture risk: a comparative study in a UK prospective cohort. Arch Osteoporos. 2016;11(1):39. doi:10.1007/s11657-016-0293-0

9. Garnero P, Munoz F, Sornay-Rendu E, Delmas PD. Associations of vitamin $\mathrm{D}$ status with bone mineral density, bone turnover, bone loss and fracture risk in healthy postmenopausal women. The OFELY study. Bone. 2007;40(3):716-722. doi:10.1016/j.bone.2006.09.026

10. Çolak Y, Afzal S, Nordestgaard BG. 25-hydroxyvitamin D and risk of osteoporotic fractures: mendelian randomization analysis in 2 large population-based cohorts. Clin Chem. 2020;66(5):676-685. doi:10.1093/clinchem/hvaa049

11. Whitmarsh T, Otake Y, Uemura K, Takao M, Sugano N, Sato Y. A cross-sectional study on the age-related cortical and trabecular bone changes at the femoral head in elderly female hip fracture patients. Sci Rep. 2019;9(1):305. doi:10.1038/s41598-018-36299-y

12. Ivaska KK, Gerdhem P, Väänänen HK, Akesson K, Obrant KJ. Bone turnover markers and prediction of fracture: a prospective follow-up study of 1040 elderly women for a mean of 9 years. $J$ Bone Miner Res. 2010;25(2):393-403. doi:10.1359/jbmr.091006

13. Bell KL, Loveridge N, Power J, et al. Structure of the femoral neck in hip fracture: cortical bone loss in the inferoanterior to superoposterior axis. J Bone Miner Res. 1999;14(1):111-119. doi:10.1359/jbmr.1999.14.1.111

14. Duboeuf F, Hans D, Schott AM, et al. Different morphometric and densitometric parameters predict cervical and trochanteric hip fracture: the EPIDOS Study. J Bone Miner Res. 1997;12(11):1895-1902. doi:10.1359/jbmr.1997.12.11.1895

15. Pulkkinen $P$, Eckstein $F$, Lochmüller EM, Kuhn V, Jämsä $T$. Association of geometric factors and failure load level with the distribution of cervical vs. trochanteric hip fractures. $J$ Bone Miner Res. 2006;21(6):895-901. doi:10.1359/jbmr.060305

16. Fisher AA, Srikusalanukul W, Davis MW, Smith PN. Clinical profiles and risk factors for outcomes in older patients with cervical and trochanteric hip fracture: similarities and differences. J Trauma Manag Outcomes. 2012;6(1):2. doi:10.1186/1752-2897-6-2

17. Cornwall R, Gilbert MS, Koval KJ, Strauss E, Siu AL. Functional outcomes and mortality vary among different types of hip fractures: a function of patient characteristics. Clin Orthop Relat Res. 2004;425:64-71. doi:10.1097/01.blo.0000132406.37763.b3

18. Fan J, Li N, Gong X, He L. Serum 25-hydroxyvitamin D, bone turnover markers and bone mineral density in postmenopausal women with hip fractures. Clin Chim Acta. 2018;477:135-140. doi:10.1016/j.cca.2017.12.015

19. Sun Q, Ge W, Hu H, et al. The influence of position of the displaced lesser trochanter on clinical outcome of unstable trochanteric femur fractures in the elderly. Biomed Res Int. 2018;2018:5013646. doi: $10.1155 / 2018 / 5013646$

20. Yoshimura N, Muraki S, Oka H, Kawaguchi H, Nakamura K, Akune T. Biochemical markers of bone turnover as predictors of osteoporosis and osteoporotic fractures in men and women: 10-year follow-up of the Taiji cohort. Mod Rheumatol. 2011;21(6):608-620. doi:10.1007/s10165-011-0455-2

21. Meinberg EG, Agel J, Roberts CS, Karam MD, Kellam JF. Fracture and dislocation classification compendium-2018. J Orthop Trauma. 2018;32(Suppl 1):S1-s170. doi:10.1097/bot.0000000000001063

22. Fox KM, Cummings SR, Williams E, Stone K. Femoral neck and intertrochanteric fractures have different risk factors: a prospective study. Osteoporos Int. 2000;11(12):1018-1023. doi:10.1007/ s001980070022 
23. Vasikaran S, Eastell R, Bruyère $\mathrm{O}$, et al. Markers of bone turnover for the prediction of fracture risk and monitoring of osteoporosis treatment: a need for international reference standards. Osteoporos Int. 2011;22(2):391-420. doi:10.1007/s00198-010-1501-1

24. Walsh JS, Henriksen DB. Feeding and bone. Arch Biochem Biophys. 2010;503(1):11-19. doi:10.1016/j.abb.2010.06.020

25. Holick MF, Binkley NC, Bischoff-Ferrari HA, et al. Evaluation, treatment, and prevention of vitamin D deficiency: an endocrine society clinical practice guideline. $J$ Clin Endocrinol Metab. 2011;96(7):1911-1930. doi:10.1210/jc.2011-0385

26. Crandall CJ, Vasan S, LaCroix A, et al. Bone turnover markers are not associated with hip fracture risk: a case-control study in the women's health initiative. J Bone Miner Res. 2018;33 (7):1199-1208. doi:10.1002/jbmr.3471

27. Verde Z, Giaquinta A, Sainz CM, Ondina MD, Araque AF. Bone mineral metabolism status, quality of life, and muscle strength in older people. Nutrients. 2019;11(11):2748. doi:10.3390/nu11112748

28. Lips P. Vitamin D deficiency and secondary hyperparathyroidism in the elderly: consequences for bone loss and fractures and therapeutic implications. Endocr Rev. 2001;22(4):477-501. doi:10.1210/ edrv.22.4.0437

29. Cauley JA, Lacroix AZ, Wu L, et al. Serum 25-hydroxyvitamin D concentrations and risk for hip fractures. Ann Intern Med. 2008;149 (4):242-250. doi:10.7326/0003-4819-149-4-200808190-00005

30. Holvik K, Ahmed LA, Forsmo S, et al. Low serum levels of 25-hydroxyvitamin D predict hip fracture in the elderly: a NOREPOS study. J Clin Endocrinol Metab. 2013;98(8):3341-3350. doi:10.1210/ jc. $2013-1468$
31. Lawton JO, Baker MR, Dickson RA. Femoral neck fractures-two populations. Lancet. 1983;322(8341):70-72. doi:10.1016/s01406736(83)90059-4

32. Larrosa M, Gomez A, Casado E, et al. Hypovitaminosis D as a risk factor of hip fracture severity. Osteoporos Int. 2012;23(2):607-614. doi:10.1007/s00198-011-1588-z

33. Gerdhem P, Ivaska KK, Alatalo SL, et al. Biochemical markers of bone metabolism and prediction of fracture in elderly women. $J$ Bone Miner Res. 2004;19(3):386-393. doi:10.1359/jbmr.0301244

34. Di Monaco M, Di Monaco R, Mautino F, Cavanna A. Femur bone mineral density, age and fracture type in 300 hip-fractured women. Aging Clin Exp Res. 2002;14(1):47-51. doi:10.1007/bf03324417

35. Wintermeyer E, Ihle C, Ehnert S, et al. Crucial role of vitamin D in the musculoskeletal system. Nutrients. 2016;8(6):319. doi:10.3390/ nu8060319

36. Fox KM, Magaziner J, Hebel JR, Kenzora JE, Kashner TM. Intertrochanteric versus femoral neck hip fractures: differential characteristics, treatment, and sequelae. J Gerontol a Biol Sci Med Sci. 1999;54(12):M635-640. doi:10.1093/gerona/54.12.m635

37. Chen PH, Wu CC, Chen WJ. Factors affect stability of intertrochanteric fractures when elderly patients fall. Biomed J. 2016;39 (1):67-71. doi:10.1016/j.bj.2015.08.007

38. Cauley JA, Lui LY, Genant HK, et al. Risk factors for severity and type of the hip fracture. J Bone Miner Res. 2009;24(5):943-955. doi:10.1359/jbmr.081246
Clinical Interventions in Aging

\section{Publish your work in this journal}

Clinical Interventions in Aging is an international, peer-reviewed journal focusing on evidence-based reports on the value or lack thereof of treatments intended to prevent or delay the onset of maladaptive correlates of aging in human beings. This journal is indexed on PubMed Central, MedLine, CAS, Scopus and the Elsevier

\section{Dovepress}

Bibliographic databases. The manuscript management system is completely online and includes a very quick and fair peer-review system, which is all easy to use. Visit http://www.dovepress.com/ testimonials.php to read real quotes from published authors. 